\title{
The role of rigid bronchoscopy in complex airway disorders
}

\author{
Alessandro Bandiera ${ }^{1, *}$, Paola Ciriaco ${ }^{1}$, Angelo Carretta ${ }^{1}$, Giampiero Negri ${ }^{1}$
}

${ }^{1}$ Department of Thoracic Surgery, San Raffaele Scientific Institute, Milan, Italy

\section{*Correspondence}

bandiera.alessandro@hsr.it

(Alessandro Bandiera)

\begin{abstract}
Rigid bronchoscopy is a diagnostic and therapeutic tool used to treat complex airways disorders. It plays a central role in the management of central airway obstruction caused by benign or malignant diseases; and requires close cooperation between the bronchoscopist and the anesthesiologist as they share the same operative field. Rigid bronchoscopy requires deep sedation or general anesthesia, intubation with the rigid bronchoscope and adequate oxygenation and ventilation during the procedure. The choice of ventilation techniques include apneic oxygenation, spontaneous assisted ventilation, controlled ventilation and jet ventilation. Rigid bronchoscopy is used to relieve respiratory symptoms due to airway obstruction by dilation for a tracheal stenosis or the mechanical debulking of endoluminal tumours, and supporting the airway by the placement of an endoluminal stent. Two types of stents are currently in use: silicone stents and metal stents with different lengths, diameters and shape configurations. They can significantly improve patients symptoms and their quality of life. Therapeutic rigid bronchoscopy, performed in appropriately selected patients and by skilled operators is effective and has a low morbidity rate.
\end{abstract}

\section{Keywords}

Rigid bronchoscopy; Central airway obstruction; Airway stenting; Ventilation techniques

\section{Introduction}

Rigid bronchoscopy is a diagnostic and therapeutic tool for the management of complex airway disorders. The first rigid bronchoscopy was described in the late 1800's by Gustav Killian for the removal of a pork bone from the airway $[1,2]$. The procedure and the equipment needed for rigid bronchoscopy was further advanced in the early 1900's by Chevalier Jackson who expanded the role of rigid bronchoscopy not only to foreign body removal but also for the treatment of complications from tuberculosis and mechanical resection of endobronchial tumours [3, 4]. With the emergence of flexible bronchoscopy the role of rigid bronchoscopy for diagnostic purposes has progressively declined since flexible bronchoscopy is less invasive, allows for the visualization of small peripheral airways and requires no deep sedation or general anesthesia. However, rigid bronchoscopy still plays a central role in the management of central airway obstruction [4, 5]. Central airway obstruction may be caused by benign or malignant diseases. Malignant causes of obstruction include primary tracheobronchial tumours and more commonly metastases or direct airway invasion from primary lung cancer, esophageal or thyroid tumours. Non malignant causes of central airway obstruction are predominately caused by post-intubation and post-tracheostomy trachea stenosis but may also be due to inflammatory diseases
$[4,5]$. The main purpose of rigid bronchoscopy is to relieve respiratory symptoms due to airway obstruction through the dilation of tracheal stenosis or the mechanical debulking of endoluminal tumours. Rigid bronchoscopy is conducted under deep sedation or general anesthesia [6]. Through the rigid bronchoscope, suction catheters, laser fibers, balloon dilators and rigid forceps may be introduced for the control of airway bleeding and the removal of endoluminal tumours [7]. Rigid bronchoscopy ensures airway control and ventilation during the procedure and allows restoration of the airway lumen which provides relief of respiratory symptoms due to increased air flow to the tracheobronchial tree. A recent prospective caseseries [8] demonstrated not only a subjective improvement of dyspnea and quality of life but also an improvement in FEV1 and FVC following therapeutic rigid bronchoscopy. Another important role of rigid broncoschopy involves airway stenting $[4,5]$. William Montgomery in the 1960's developed silicone T-tube stents [9]. The first completely endoluminal airway stent was placed in 1985 by Jean Francois Dumon [10]. Since then, airway stenting via rigid bronchoscopy has been widely used for extrinsic airway compression and mixed disease with airway compromise. Currently, there are two kinds of stents: metal and silicone stents. With the increasing number of central airway obstructions and the advances in associated treatment options, rigid bronchoscopy 
continues to play a pivotal role in the management of airway obstruction. Thoracic surgeons, interventional pulmonologists and intensivists need to be skilled in this practice. Today, most cases are managed in an emergency or ICU setting due to airway compromise or respiratory failure from severe and complex airway disorders. Close cooperation between thoracic surgeons, anesthesiologists, and intensivists is mandatory for the success of rigid bronchoscopy procedures.

\section{Equipment}

A rigid bronchoscope consists of a hollow metal tube with a bevel at the distal edge. The rigid bronchoscope is available in several lengths and sizes. Bronchoscopes are longer than tracheal scopes to allow access to the main stem bronchi. The distal bevel is essential for recanalization of the obstructed airway in coring out and removing endoluminal tumours. The distal portion of the bronchoscopes have fenestrations for contralateral ventilation while working in the bronchial tree. The inner diameter varies between 7-13 $\mathrm{mm}$ and the outer diameter varies between $8-14 \mathrm{~mm}$. The wall is generally $2-3 \mathrm{~mm}$. At the proximal edge, several ports are present for attachment of various ventilatory devices and for introduction of cameras, light and ancillary instruments. A variety of instruments can be inserted through the operative channel of a rigid bronchoscope [7], these include a flexible bronchoscope for suction of secretions and blood, rigid suction catheters, various types of rigid forceps, rigid and balloon dilators, baskets, laser probes, electrocautery, cryotherapy and argon plasma catheters, microdebriders and devices for positioning of airway stents [11]. Fig. 1 shows various sizes of rigid tracheal scopes and rigid bronchoscopes with cameras, forceps and a ventilatory device.

\section{Anesthesia and ventilation}

Rigid bronchoscopy requires communication and interaction between the bronchoscopist and the anesthesiologist who share a common work space. The airway may be severely compromised, therefore cooperation and planning of the procedure is crucial for the safety of the patient. Rigid bronchoscopy requires deep sedation or general anesthesia, intubation with the rigid bronchoscope and adequate oxygenation and ventilation during the procedure [6].

Intravenous anesthesia is generally the preferred technique. The use of inhaled anesthetics is very rare since the rigid intubation is an open system with the possibility of the anesthetic contaminating the operating room. A rigid bronchoscope is inserted only under deep sedation usually requiring a combination of hypnotic and narcotic agents with rapid effect to allow full recovery to baseline respiratory function at the end of the procedure in patients with marginal pulmonary status. Propofol (40-200 $\mathrm{mcg} / \mathrm{kg} / \mathrm{min})$ and remifentanil (0.05$0.5 \mathrm{mcg} / \mathrm{kg} / \mathrm{min}$ ) are the most commonly used agents [5, 6, 12]. Paralysis is not always required but Pathak et al. [6], in a review of ventilation and anesthetic approaches for rigid bronchoscopy, suggest the use of neuromuscular blocking agents in order to reduce hypnotic doses. In their experience, the drugs of choice were vecuronium or cisatracurium while rocuronium and pancuronium were considered inadequate because of their
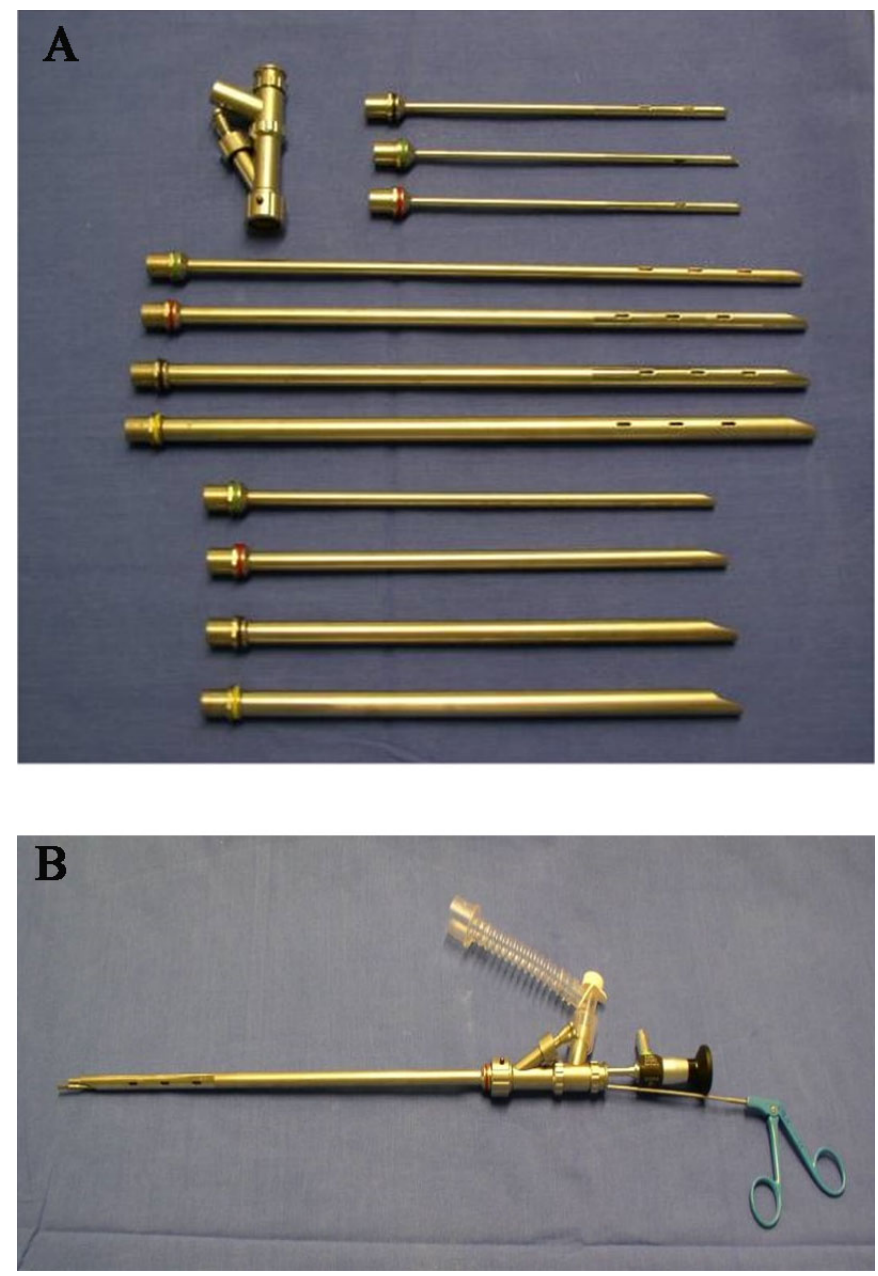

FIGURE 1. Shows rigid tracheal scopes and rigid bronchoscopes. Rigid bronchoscopes may have different sizes. Several ports are present at the proximal edge for the attachment of various ventilatory devices and for the introduction of cameras, light and ancillary instruments. (A) shows rigid tracheal scopes and rigid bronchoscopes of different lengths and sizes. (B) shows rigid bronchoscope with camera, forceps and a ventilatory device.

longer half-life. General anesthesia with neuromuscular blockade is a valid and effective technique used in the majority of institutions [13]. Reversal of paralysis at the end of the procedure is recommended as patients generally suffer from respiratory compromise and cannot tolerate any residual neuromuscular blockade [6].

Once the induction anesthesia is established, hyperextension of the neck is required for the insertion of the rigid bronchoscope. It is very important to assess neck mobility with particular attention to cervical spine instability or limited range of motion which can occur with spondylosis. The patient is positioned with a shoulder roll and the head of the bed is lowered, permitting the head to lean against the bed without floating. The oral cavity and jaw mobility should be checked and a mouth guard should be used to protect the upper teeth. The rigid bronchoscope is inserted through the mouth with the bevel towards the tongue and is advanced under the epiglottis. Once the glottis is visualized the bronchoscope is rotated 90 degrees so that the bevel can pass through the vocal cords 
without trauma. Inside the trachea the scope is rotated another 90 degrees and the bevel is positioned on the posterior portion of the trachea [4, 5]. Fig. 2 shows the external view of a rigid bronchoscope.

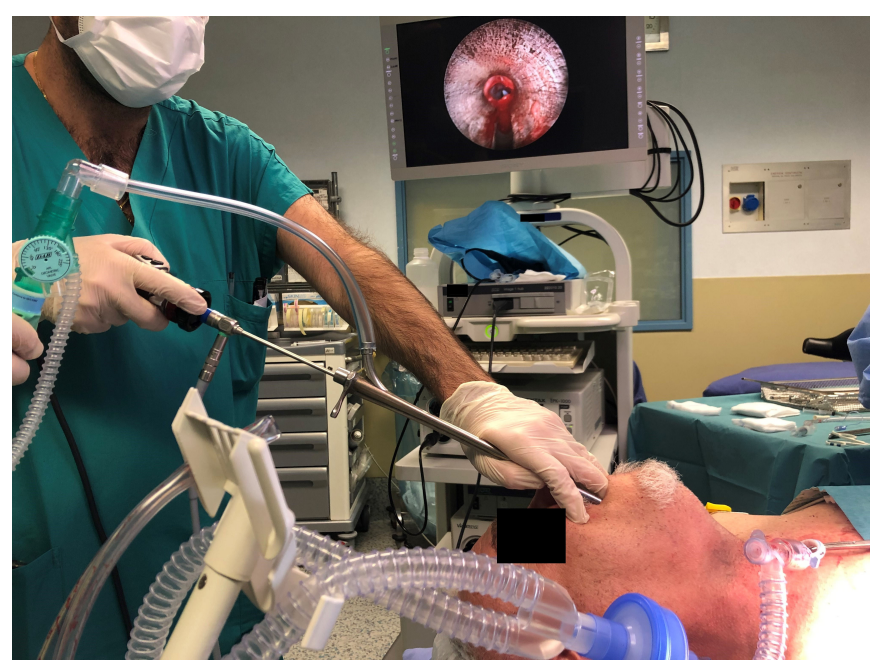

FIGURE 2. Shows the external view of a rigid bronchoscopy. Patient's neck is hyperextended to allow rigid intubation. Ventilatory support is connected to the proximal port of the bronchoscope. The figure shows a rigid bronchoscopy performed for dilating a benign tracheal stenosis proximal to the tracheostoma and for positioning a Montgomery T-tube.

Once intubation is complete adequate oxygenation and ventilation should be established and maintained through an uncuffed endotracheal tube and an open system.

Because of lack of standardization in ventilation techniques the choice of ventilation methods is generally dictated by local expertise [6]. The available techniques are: apneic oxygenation, spontaneous assisted ventilation, controlled ventilation and jet ventilation. In the apneic ventilation technique, cycles of oxygenation and ventilation are interrupted by cycles of apnea to perform the bronchoscopic procedures. This results in the development of peri-operative acidosis [14]. In the spontaneous assisted ventilation technique, the patient maintains ventilation and supplemental oxygen is supplied through the bronchoscope with anesthesia support via bag ventilation attached to the bronchoscope in the phases of deeper sedation. Complications with this technique include hypoxemia, bronchospasm and laryngospasm; but the technique is considered safe and effective for the avoidance of neuromuscular blocking drugs, and lowering the risk of post-procedural reintubation [15]. In controlled ventilation, the rigid bronchoscope is used as an endotracheal tube. All the proximal ports must be covered with silastic caps and the mouth is packed with gauze to reduce air leaks. This technique can make it difficult for the passage of the instruments through the bronchoscope during the procedure but has the advantage of improving ventilation and oxygenation in patients with less respiratory reserve [15]. Persistent circuit leaks can make this technique challenging. Puma et al. [16] described an alternative technique for airway management which consists of positioning a small bore orotracheal tube beyond the stenosis in combination with the rigid bronchoscope which is inserted parallel to the ventilation tube. With this approach, the airway is always under anesthesiological control during all the phases of the procedure.

A common ventilatory approach for rigid bronchoscopy is jet ventilation. Jet ventilation is applied through small bore catheters connecting the ventilator and the ventilation port of the rigid bronchoscope [6]. Jet ventilation uses a high pressure oxygen source and gas is delivered to the patient at supraphysiologic respiratory rates. The automated jet ventilator may free the anesthesiologist from manual ventilation. Using the jet ventilation technique the working channel of the rigid bronchoscope is completely open and several instruments can be easily introduced. Complications of jet ventilation include hypercarbia, hypoxia and hypotension, especially in sicker patients, as well as cases of barotrauma ranging from cervical emphysema to tension pneumothorax [17-21]. The use of external ventilation, such as intermittent negative pressure ventilation and external high frequency oscillation, has also been reported with good results [22, 23].

Techniques for ventilation may vary between Institutions according to local expertise, clinical needs and the availability of instruments.

\section{Specific indications}

The main indication for rigid bronchoscopy is the diagnosis and management of central airway obstruction [24]. Most of these cases require urgent treatment to relieve obstructive symptoms. This treatment may be lifesaving and in intubated patients, allows for successful extubation and ultimately discharge from the ICU [25]. Central airway obstruction may be due to malignant and benign disease. Table 1 lists the main causes of central airway obstruction. Malignant cases, especially lung cancer outnumber non- malignant cases [5]. Patients with malignant central airway obstruction have a poor prognosis [26]. Bronchoscopic intervention does not influence survival as demonstrated by Chhajed et al. [27] but may improve quality of life and performance status [28-30]. Murgu et al. [31] demonstrated the success of bronchoscopic interventions to restore airway patency in the treatment of intubated patients with respiratory failure caused by central airway obstruction from NSCLC. In their experience, the removal of mechanical ventilation was possible in more than $80 \%$ of cases and allowed patients to receive cancer specific therapy. Malignant central airway obstruction may be caused by primary airway neoplasms and more frequently by metastases or direct invasion by other tumours [4, 5]. Therapeutic strategies to manage malignant central airway obstruction vary according to the pattern of airway involvement. Malignant obstructions may be totally intra-luminal without involvement of the tracheal wall, due to an extrinsic compression and, more frequently, mixed with external compression associated with an intraluminal tumour [4, 5]. The goal of treatment is to establish patency of the airway. In some cases bronchoscopic treatment may be the bridge to cancer specific treatment such as surgical excision of the tumour. In intrinsic obstruction, the treatment mainly involves removal of an endoluminal tumour. The debulking procedure consists of laser coagulation of the tumour, mechanical coring with the rigid bronchoscope and co- 
T A B L E 1. Main causes of central airway obstruction

\begin{tabular}{ll}
\hline Benign causes & Malignant causes \\
\hline Post-intubation stenosis & Primary adenoid cystic carcinoma \\
\hline Post-tracheostomy stenosis & Primary squamous cell carcinoma \\
\hline Surgical anastomosis & Primary carcinoid \\
\hline Immunological disorders like granulomatosis with polyangioitis & Primary mucoepidermoid carcinoma \\
\hline Tracheomalacia & Metastatic carcinoma to the airway \\
\hline Sarcoidosis & Bronchogenic carcinoma \\
\hline Tubercolosis & Laryngeal carcinoma \\
\hline Idiopathic & Esophageal carcinoma \\
\hline Hamartoma & Thyroid tumours \\
\hline Papilloma & Lymphoma \\
\hline Mucus plug and blood clot & Lymphadenopathy \\
\hline
\end{tabular}

agulation of the implant. Fig. 3 shows an intraluminal tumour, its mechanical removal and airway patency after the debulking. In some cases the placement of a stent may be indicated. An extrinsic compression requires a dilation and a stent placement. A mixed obstruction is treated by removing the endoluminal portion of the tumour and stenting the airway. Vishwanath $e t$ al. [32] demonstrated that bronchoscopic debulking is safe and effective in more than $80 \%$ of cases. In the large experience of Cavaliere et al. $[33,34]$ better results were observed in the debulking of larger airways rather than lobar branches.

The most common etiology of benign airway stenoses is due to post-intubation and post-tracheostomy disorders [35, 36]. These stenoses may be simple, when only the mucosa is involved, and complex in cases involving the airway wall with cartilage instability. Fig. 4 shows a complex tracheal postintubation stenosis. The goal of treatment of a benign stenosis is curative and patients should be evaluated for radical surgical resection. Bronchoscopic treatment may be considered as a bridge to surgery but may also be curative in cases where surgery is contraindicated due to the characteristics of the stenosis (excessive length, tissue inflammation) or the patient's inability to undergo surgery. Endoscopic treatment leads to an immediate relief of symptoms. Several techniques may be performed via rigid bronchoscopy such as argon plasma coagulation, cryotherapy, balloon dilation and stent placement.

Other causes of benign airway stenosis include anastomotic narrowing after surgery, immunological disorders, such as granulomatosis with polyangioitis or inhalation injury. In immunological related airway stenoses, in addition to mechanical dilation, submucosal instillation of long-acting corticosteroids may result in clinical benefit [37].

Rigid bronchoscopy maintains an important role in foreign body removal because it allows for explantation of the foreign body and the possibility of airway control [38]. Flexible bronchoscopy has a high rate of success in removal of foreign bodies and is effective in about $90 \%$ of cases [39]. The failure of flexible bronchoscopy necessitates rigid bronchoscopy. In several cases the combined use of rigid and flexible bronchoscopy may offer the highest success rate [4].

Rigid bronchoscopy is also a useful tool in cases of hemoptysis. The large operative channel allows for good visualiza- tion during the procedure. Several instruments can be used, especially suction catheters, and the airway is always under control. The rigid bronchoscope may tamponade the bleeding source and, if necessary, selective lung intubation can be obtained. As reported by Flannery et al. [4] in massive or life threatening hemorrhage the use of rigid bronchoscopy is mandatory for airway stabilization, suction of blood and clots and the potential use of hemostatic techniques including argon and laser coagulation [40-45].

\section{Airway stenting}

The goal of tracheal and bronchial stenting is to ensure airway patency. Stenting should be considered for those lesions causing symptoms or a reduction of the tracheal lumen by more than $50 \%$ to $80 \%$. The first airway stents were placed by Trendelenburg and Bond at the end of 1800's [46-48]. In 1965, William Montgomery [9] designed a silicone T-tube for the treatment of tracheal stenosis. The T-tube requires a tracheostomy for its placement. It allows tracheal recanalization with longitudinal limbs and has no risk of migration thanks to the horizontal limb which exits from the stoma. The use of this stent is particularly useful in the management of complex benign tracheal stenoses as an alternative for adjuvant treatment to surgery [49]. The first totally endoluminal stent was introduced by Jean Francois Dumon in 1985 [10]. For extrinsic, intrinsic and mixed airway obstructions, airway stents can be effective for maintenance of airway patency. Airway stents can be used in the treatment of benign stenosis, support collapsing airways in malacia and in management of fistulas. In benign stenoses, it is important to consider that a stent prosthesis is a foreign body which may lead to complications such as granulation and fistula formation. The ideal stent should be easy to place and remove, biologically inert without causing significant inflammation of the airway; and should not migrate or cause obstruction. Two stents currently in use are silicone and metal stents. Stents may have different lengths, diameters and shapes. They may be straight or bifurcated (Y stents) and are selected for use based on airway anatomy, operator expertise, stent availability and patient factors.

Silicone stents are available in several sizes and shapes such 


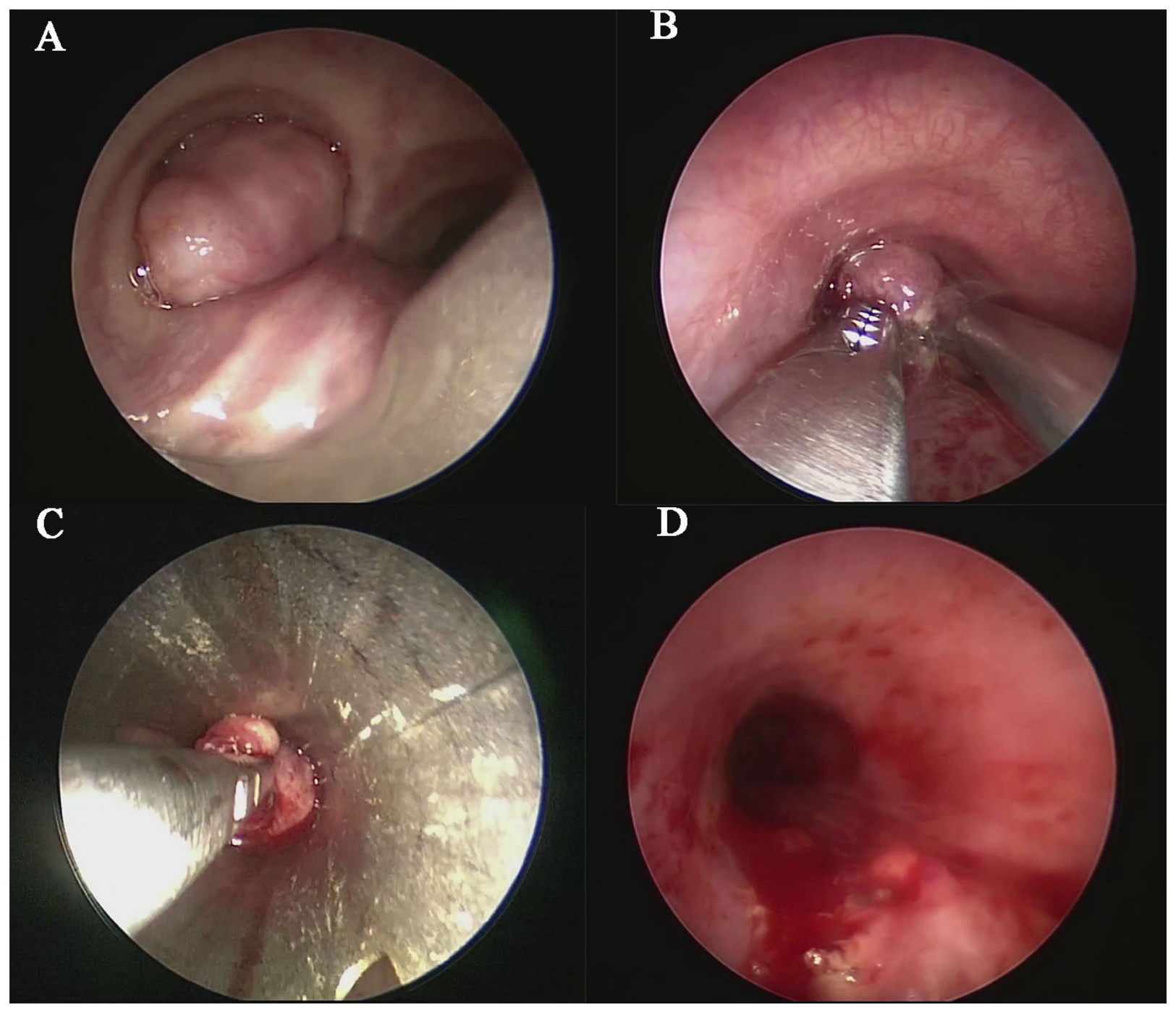

F I G U R E 3. Shows an intraluminal tumour, its mechanical removal and airway patency after the debulking. (A) shows an endoluminal tumour in the left main bronchus causing an airway obstruction greater than 50\%. (B) shows the coagulation of the tumour implant. (C) shows the mechanical removal of the tumour with rigid forceps after coring or the corkscrew technique. (D) shows left main bronchus patency at the end of the debulking maneuver with only mild signs of bleeding.

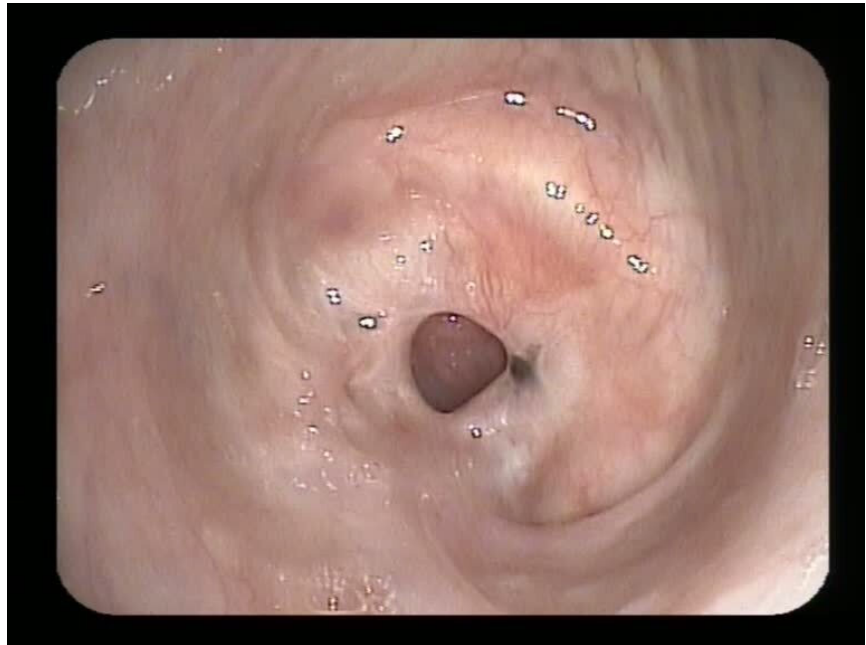

F I G U RE 4. Shows a benign complex post-intubation stenosis. as straight or bifurcated. At the external surface of these stents, studs are present as anchors to the trachea wall preventing migration and minimizing the risk of granulation or ischemia. Radiopaque studs aid radiological visualization. The stent should extend about $0.5 \mathrm{~cm}$ above and below the stenotic segment. The maximum diameter of the stent that can be placed is limited by the caliber of the rigid bronchoscope. The estimation of the diameter of the stent can be made from CT scan measurements or from the use of a balloon dilator. The length of the stent is obtained from bronchoscopic measurements using the camera or flexible bronchoscopy. Silicone stents can be customized at the time of the procedure [50], can be adjusted after deployment, and can be easily removed. Tay et al. [51] described the successful treatment of a tortuous difficult airway stenosis by angulated stents resulting from cutting and suturing a silicone prosthesis to adjust the stent to the angulated stenosis. Silicone stent insertion and removal requires rigid bronchoscopy and general anesthesia. In addition to higher resource requirements, silicone stents have the potential for migration, mucostasis and granulation 
tissue formation [52-54]. Efforts have been made to create silicone stents which mimic physiological movements of the trachea such as the dynamic stent [55] and the natural stent [56].

Metallic stents are self-expandable and may be uncovered, partially covered or completely covered. For their placement rigid bronchoscopy is not necessarily required [4], but is preferable for better airway control. Metallic stents are not recommended in benign tracheal stenosis because they are difficult to remove and may lead to airway injuries [57]. At present, metallic stents are hybrid with metallic framework covered by silicone, polyester or polytetrafluoroethylene [58]. Good results have been recently reported with fully covered metal stents in the treatment of benign airway stenosis [59]. Metallic self-expanding stents usually represent a good choice in malignant central airway obstruction when the primary goal is palliation because they are easily deployed [60]. Self expandable metal stents can be particularly useful in cases of excessive tortuosity of the airway or in cases of stenoses with different diameters between the proximal and the distal trachea [4].

Research has led to the improvement of stent technology with the development of biodegradable, drug-eluting and three dimensional printed stents. Biodegradable stents can be very useful in benign stenosis to avoid long-term complications. The design, degradation time and mechanical properties of these devices are still being investigated and only a few cases have been described in humans [61]. Drug-eluting stents using antifibrotic drugs could be incorporated for the prevention of granulation, but this is currently limited because of licensure issues due to the inclusion of a pharmaceutically active product [62]. Three dimensional printing technology can be used to tailor stents for specific airway anatomy and with adequate expansion force [62, 63]. As discussed by Freitag et al. [62] the production and use of these stents could be hindered by costs and legal issues since all production steps are subject to inspection and validation procedures.

Another group of disorders which may require treatment with a stent are fistulas. Tracheoesophageal fistulas should always be closed. If surgical repair is not feasible a stent should be placed; either using an esophageal stent, a tracheal stent or both [60, 64, 65]. Some authors [66] reported that double stenting of the airway and esophagus can achieve the best clinical results, but other studies [67] did not find significant differences between patients who received a single tracheal stent, a single esophageal stent or double stenting. Since there is a paucity of evidence, practices among centers may vary. In the study by Herth et al. [68] all patients who underwent stenting either in the airway, esophagus or both systems were successfully treated and improved their quality of life.

Anastomotic dehiscence or stenosis after tracheal surgery, sleeve resections and transplants may also be treated by stent placement.

The choice of the type of stent depends on the type of obstruction, airway anatomy, the patient's general condition, operator expertise and the available prosthesis. The operator; a thoracic surgeon, interventional pulmonologist or intensivist, should have expertise in these kind of procedures. Although the choice of the procedure should be ideally discussed in a team meeting, these maneuvers may need to be performed in an urgent setting.

Complications related to stent placement include migration, mucus plugging, airway infection, granulation tissue, tumour ingrowth and halitosis (Table 2). Infection occurs in more than $15 \%$ of cases [69]. Expert post-procedural care is essential to limit complications. Patients should use mucolytics to reduce mucoid plugs and infections, and undergo periodic bronchoscopies, and long-term stents should be replaced periodically.

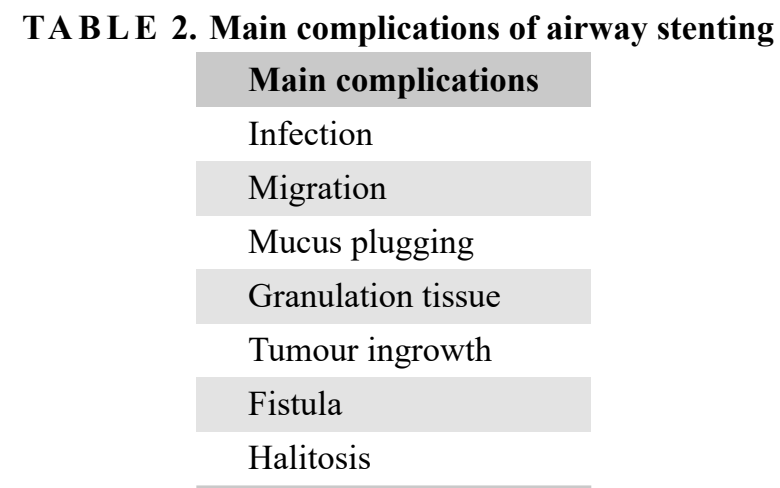

In view of the potential complications of stent placement, this procedure should be considered only after the failure of other therapeutic options. The Silicone Prosthesis in Obstructive Lung Cancer (SPOC) trial [70] reported that airway stents should be considered palliative only after other treatments have failed. In benign conditions, the use of stents produce immediate relief but may be associated with the onset of granulation tissue which may result in obstruction. Benign obstructions should be considered for surgery and stent placement should be taken into consideration only in those cases not suitable for surgery.

For all the above reasons, the incidence of stent placement has progressively decreased [71]. According to a recent survey [13] airway stenting is performed under general anesthesia in the majority of European countries; but nine countries out of 26 reported airway stenting activity under local anesthesia. These data probably reflect the lack of skills in rigid bronchoscopy, the difficulty in some countries to access an operating room, and low volume to justify a dedicated operative room. For these reasons, flexible bronchoscopy is still used for the deployment of airway stents despite the advantages of rigid bronchoscopy. Another important point that emerged from this survey which may limit airway stenting activity is that 10 out of 26 countries reported issues with reimbursement.

\section{Complications}

Complications related to rigid bronchoscopy are uncommon and include sore throat, neck pain, injury to the teeth and lips and tears of the airway wall. Cardiac arrhythmias and ischemia induced by hypoxemia are the most serious complications. A multicenter registry on therapeutic bronchoscopy [72] reported a complication rate and a mortality rate for rigid bronchoscopy of $3.4 \%$ and $0.5 \%$; respectively. Complications following interventional bronchoscopy were associated with American Society of Anesthesiologists (ASA) greater than 3, emergent procedures and re-do therapeutic procedures. In 
this study the 30-day mortality for rigid bronchoscopy was $17.5 \%$. The overall 30 -day mortality was associated with ASA score greater than 3 , intrinsic or mixed obstructions and stent positioning. The association of 30-day mortality with stent placement probably reflects the fact that patients requiring stents generally have a more advanced disease without any other treatment option. Specific complications of stent placement include infections, stent migration and obstruction due to mucoid impaction, granulation tissue or tumour ingrowth. Stents require periodic replacement and their use should be limited to those cases without any other therapeutic option.

\section{Conclusions}

Rigid bronchoscopy is an effective tool in the treatment of severe and complex airway disorders both in malignant and benign diseases and allows prompt relief of respiratory symptoms. The procedure consists of the introduction in the airway of a hollow metal tube which may be used with ancillary instruments for the dilation of an airway stenosis, for the debulking of an intraluminal tumour or for the deployment of a stent with the aim of ensuring airway patency. Rigid bronchoscopy is generally performed in an urgent setting for severe respiratory distress. The management of patients may be very challenging and requires close cooperation between the operator and the anesthesiologist as they share the same operative field. The procedure is generally performed under general anesthesia with neuromuscular blockade or deep sedation. Several ventilation techniques are available and they should be chosen according to local expertise, patient characteristics and equipment availability. Patients requiring a rigid bronchoscopy generally have marginal respiratory function and short action drugs should be used in order to rapidly restore normal respiratory activity at the end of the procedure avoiding anesthesia complications.

Rigid bronchoscopy and associated procedures, performed in an appropriate setting and by skilled operators can significantly relieve symptoms and improve quality of life. There is still a lack of standardization in the practice of rigid bronchoscopy. Most of the cases are managed in an urgent setting and the knowledge of bronchoscopic techniques, anesthetic care, ablative methods and stenting is crucial for the success of the procedure in critically ill patients with complex airway disorders.

Despite the advantages of rigid bronchoscopy, its use is limited in some countries [13] and some operators prefer flexible bronchoscopy. This may be due to limited physician skills with this technique, a limited number of cases to achieve proficiency, and limited access to a dedicated operating room devoted to rigid bronchoscopy procedures.

\section{AUTHOR CONTRIBUTIONS}

AB, PC, AC designed the study; AB wrote the manuscript; PC, $\mathrm{AC}, \mathrm{GN}$ revised the manuscript; All authors read and approved the final manuscript.

\section{ACKNOWLEDGMENT}

I would like to express my gratitude to all those who helped me during the writing of this manuscript. Thanks to all the peer reviewers for their opinions and suggestions.

\section{CONFLICT OF INTEREST}

The authors declare no competing interests.

\section{REFERENCES}

[1] Kollofrath O. Entfernung eines Knochenstucks ausdem rechten Bronchus auf naturlichem Wege und unter Anwendung der directen Laryngoscopie. Munch Med Wochenschrift. 1897; 38: 1038-1039. (In German)

[2] Becker HD, Marsh BR. History of the rigid bronchoscope (pp. 2-15). Interventional bronchoscopy. Basel (Switzerland): Karger Publishers. 2000 .

[3] Jackson C. Foreign bodies in the air and food passages: charted experience in cases from no. 631 to no. 1155 at the Bronchoscopic Clinic. New Bedford (MA): Reynolds. 1924.

[4] Flannery A, Daneshvar C, Dutau H, Breen D. The art of rigid bronchoscopy and airway stenting. Clinics in Chest Medicine. 2018; 39 : 149-167.

[5] Semaan R, Yarmus L. Rigid bronchoscopy and silicone stents in the management of central airway obstruction. Journal of Thoracic Disease. 2015; 7: S352-S362.

[6] Pathak V, Welsby I, Mahmood K, Wahidi M, MacIntyre N, Shofer S. Ventilation and anesthetic approaches for rigid bronchoscopy. Annals of the American Thoracic Society. 2015; 11: 628-634.

[7] Dutau H, Vandemoortele T, Breen DP. Rigid bronchoscopy. Clinics in Chest Medicine. 2013; 34: 427-435.

[8] Mahmood K, Wahidi MM, Thomas S, Argento AC, Ninan NA, Smathers $\mathrm{EC}$, et al. Therapeutic bronchoscopy improves spirometry, quality of life, and survival in central airway obstruction. Respiration. 2015; 89: 404413.

[9] Montgomery WW. T-tube tracheal stent. Archives of Otolaryngology. 1965; 82: 320-321

[10] Dumon JF. A dedicated tracheobronchial stent. Chest. 1990; 97: 328-332.

[11] Yarmus L, Ernst A, Feller-Kopman D. Emerging technologies for the thorax: indications, management and complications. Respirology. 2010; 15: 208-219.

[12] José RJ, Shaefi S, Navani N. Anesthesia for bronchoscopy. Current Opinion in Anaesthesiology. 2014; 27: 453-457.

[13] Dutau H, Breen D, Bugalho A, Dalar L, Daniels J, Dooms C, et al. Current practice of airway stenting in the adult population in Europe: a survey of the European Association of Bronchology and Interventional Pulmonology (EABIP). Respiration. 2018; 95: 44-54.

[14] Frumin MJ, Epstein RM, Cohen G. Apneic oxygenation in man. Anesthesiology. 1959; 20: 789-798.

[15] Perrin G, Colt HG, Martin C, Mak MA, Dumon JF, Gouin F. Safety of interventional rigid bronchoscopy using intravenous anesthesia and spontaneous assisted ventilation. A prospective study. Chest. 1992; 102: 1526-1530.

[16] Puma F, Meattelli M, Kolodziejek M, Properzi MG, Capozzi R, Matricardi A, et al. An alternative method for airway management with combined tracheal intubation and rigid bronchoscope. Annals of Thoracic Surgery. 2019; 107: e435-e436.

[17] Buczkowski PW, Fombon FN, Lin ES, Russell WC, Thompson JP. Air entrainment during high-frequency jet ventilation in a model of upper tracheal stenosis. British Journal of Anaesthesia. 2007; 99: 891-897.

[18] Fernandez-Bustamante A, Ibañez V, Alfaro JJ, de Miguel E, Germán MJ, Mayo A, et al. High-frequency jet ventilation in interventional bronchoscopy: factors with predictive value on high-frequency jet ventilation complications. Journal of Clinical Anesthesia. 2006; 18: 349356.

[19] Godden DJ, Willey RF, Fergusson RJ, Wright DJ, Crompton GK, Grant 
IW. Rigid bronchoscopy under intravenous general anaesthesia with oxygen Venturi ventilation. Thorax. 1987; 37: 532-534.

[20] Hautmann H, Gamarra F, Henke M, Diehm S, Huber RM. High frequency jet ventilation in interventional fiberoptic bronchoscopy. Anesthesia and Analgesia. 2000; 90: 1436-1440.

[21] Conacher ID, Paes LL, McMahon CC, Morritt GN. Anesthetic management of laser surgery for central airway obstruction: a 12-year case series. Journal of Cardiothoracic and Vascular Anesthesia. 1998; 12: 153-156.

[22] Natalini G, Cavaliere S, Vitacca M, Amicucci G, Ambrosino N, Candiani A. Negative pressure ventilation vs. spontaneous assisted ventilation during rigid bronchoscopy. a controlled randomised trial. Acta Anaesthesiologica Scandinavica. 1998; 42: 1063-1069.

[23] Natalini G, Cavaliere S, Seramondi V, Foccoli P, Vitacca M, Ambrosino $\mathrm{N}$, et al. Negative pressure ventilation vs external high-frequency oscillation during rigid bronchoscopy. A controlled randomized trial. Chest. 2000; 118: 18-23.

[24] Batra H, Yarmus L. Indications and complications of rigid bronchoscopy. Expert Review of Respiratory Medicine. 2018; 12: 509-520.

[25] Colt HG, Harrell JH. Therapeutic rigid bronchoscopy allows level of care changes in patients with acute respiratory failure from central airways obstruction. Chest. 1997; 112: 202-206.

[26] Vonk-Noordegraaf A, Postmus PE, Sutedja TG. Tracheobronchial stenting in the terminal care of cancer patients with central airways obstruction. Chest. 2001; 120: 1811-1814.

[27] Chhajed PN, Baty F, Pless M, Somandin S, Tamm M, Brutsche MH. Outcome of treated advanced non-small cell lung cancer with and without central airway obstruction. Chest. 2006; 130: 1803-1807.

[28] Monnier P, Mudry A, Stanzel F, Haeussinger K, Heitz M, Probst R, et al. The use of the covered Wallstent for the palliative treatment of inoperable tracheobronchial cancers. A prospective, multicenter study. Chest. 1996; 110: 1161-1168.

[29] Gilmartin JJ, Veale D, Cooper BG, Keavey PM, Gibson GJ, Morritt GN. Effects of laser treatment on respiratory function in malignant narrowing of the central airways. Thorax. 1987; 42: 578-582.

[30] Zaric B, Kovacevic T, Stojsic V, Sarcev T, Kocic M, Urosevic M, et al. Neodymium yttrium-aluminium-garnet laser resection significantly improves quality of life in patients with malignant central airway obstruction due to lung cancer. European Journal of Cancer Care. 2015; 24: 560-566.

[31] Murgu S, Langer S, Colt H. Bronchoscopic intervention obviates the need for continued mechanical ventilation in patients with airway obstruction and respiratory failure from inoperable non-small-cell lung cancer. Respiration. 2012; 84: 55-61.

[32] Vishwanath G, Madan K, Bal A, Aggarwal AN, Gupta D, Agarwal R. Rigid bronchoscopy and mechanical debulking in the management of central airway tumors: an Indian experience. Journal of Bronchology \& Interventional Pulmonology. 2013; 20: 127-133.

[33] Cavaliere S, Venuta F, Foccoli P, Toninelli C, La Face B. Endoscopic treatment of malignant airway obstructions in 2,008 patients. Chest. 1997; 110: 1536-1542.

[34] Cavaliere S, Foccoli P, Farina PL. Nd: YAG laser bronchoscopy. A fiveyear experience with 1,396 applications in 1,000 patients. Chest. 1988; 94: 15-21.

[35] Grillo HC, Donahue DM. Post intubation tracheal stenosis. Seminars in Thoracic and Cardiovascular Surgery. 1996; 8: 370-380.

[36] Wain JC. Postintubation tracheal stenosis. Chest Surgery Clinics of North America. 2003; 13: 231-246.

[37] Zycinska K, Wardyn K, Zielonka TM, Nitsch-Osuch A, Zarzycki S, Demkow U, et al. Subglottic and tracheal stenosis due to Wegener's granulomatosis. Advances in Experimental Medicine and Biology. 2013; 755: 221-224.

[38] Rafanan AL, Mehta AC. Adult airway foreign body removal. What's new? Clinics in Chest Medicine. 2001; 22: 319-330.

[39] Sehgal IS, Dhooria S, Ram B, Singh N, Aggarwal AN, Gupta D, et al. Foreign body inhalation in the adult population: experience of 25,998 bronchoscopies and systematic review of the literature. Respiratory Care. 2015; 60: 1438-1448.

[40] Marsico G, Guimares C, Montesi J. Management of massive hemoptysis with rigid bronchoscopy and cold saline solution. Jornal de Pneumologia. 2003; 29: 1590-600.
[41] McCollun WB, Mattox KL, Guinn GA, Beall AC. Immediate operative treatment for massive hemoptysis. Chest. 1975; 67: 152-155.

[42] Gourin A, Garzon AA. Operative treatment of massive hemoptysis. Annals of Thoracic Surgery. 1974; 18: 52-60.

[43] Garzon AA, Cerruti M, Gourin A, Karlson KE. Pulmonary resection for massive hemoptysis. Surgery. 1970; 67: 633-638.

[44] Dweik RA, Stoller JK. Role of bronchoscopy in massive hemoptysis. Clinics in Chest Medicine. 1999; 20: 89-105.

[45] Bobrowitz ID, Ramakrishna S, Shim YS. Comparison of medical v surgical treatment of major hemoptysis. Archives of Internal Medicine. 1983; 143: 1343-1346.

[46] Trendelenburg F. Beitra“ ge zu den Operationen an den Luftwegen. Langenbecks Archiv für Chirurgie. 1872; 13: 335. (In German)

[47] Bond CJ. Note on the treatment of tracheal stenosis by a new T-shaped tracheotomy tube. The Lancet. 1891; 137: 539.

[48] Panchabhai TS, Mehta AC. Historical perspectives of bronchoscopy. Connecting the dots. Annals of the American Thoracic Society. 2015; 12: 631-641.

[49] Carretta A, Casiraghi M, Melloni G, Bandiera A, Ciriaco P, Ferla L, et al. Montgomery T-tube placement in the treatment of benign tracheal lesions. European Journal of Cardio-Thoracic Surgery. 2009; 36: 352-356.

[50] Breen DP, Dutau H. On-site customization of silicone stents: towards optimal palliation of complex airway conditions. Respiration. 2009; 77: 447-453.

[51] Tay CK, Jeong B, Kim H. Angulated stents-a novel stent improvisation to manage difficult post-tuberculosis bronchial stenosis. American Society for Artificial Internal Organs. 2018; 64: 565-569.

[52] Bolliger CT, Probst R, Tschopp K, Solèr M, Perruchoud AP. Silicone stents in the management of inoperable tracheobronchial stenoses. Indications and limitations. Chest. 1993; 104: 1653-1659.

[53] Mitsuoka M, Sakuragi T, Itoh T. Clinical benefits and complications of Dumon stent insertion for the treatment of severe central airway stenosis or airway fistula. General Thoracic and Cardiovascular Surgery. 2007; 55: 275-280

[54] Martinez-Ballarin JI, Diaz-Jimenez JP, Castro MJ, Moya JA. Silicone stents in the management of benign tracheobronchial stenoses. Tolerance and early results in 63 patients. Chest. 1996; 109: 626-629.

[55] Freitag L, Eicker R, Linz B, Greschuchna D. Theoretical and experimental basis for the development of a dynamic airway stent. European Respiratory Journal. 1994; 7: 2038-2045.

[56] Park HY, Kim H, Koh WJ, Suh GY, Chung MP, Kwon OJ. Natural stent in the management of post-intubation tracheal stenosis. Respirology. 2009; 14: 583-588.

[57] Gaissert HA, Grillo HC, Wright CD, Donahue DM, Wain JC, Mathisen DJ. Complication of benign tracheobronchial strictures by self-expanding metal stents. Journal of Thoracic and Cardiovascular Surgery. 2003; 126 : 744-747.

[58] Avasarala SK, Freitag L, Mehta AC. Metallic endobronchial stents: a contemporary resurrection. Chest. 2019; 155: 1246-1259.

[59] Fortin M, Lacasse Y, Elharrar X, Tazi-Mezalek R, Laroumagne S, Guinde $\mathrm{J}$, et al. Safety and efficacy of a fully covered self-expandable metallic stent in benign airway stenosis. Respiration. 2017; 93: 430-435.

[60] Lee P, Kupeli E, Mehta AC. Airway stents. Clinics in Chest Medicine. 2010; 31: 141-150, Table of Contents.

[61] Dutau H, Musani AI, Laroumagne S, Darwiche K, Freitag L, Astoul P. Biodegradable airway stents - bench to bedside: a comprehensive review. Respiration. 2015; 90: 512-521.

[62] Freitag L, Gördes M, Zarogoulidis P, Darwiche K, Franzen D, Funke F, et al. Towards individualized tracheobronchial stents: technical, practical and legal considerations. Respiration. 2016; 94: 442-456.

[63] Cheng GZ, San Jose Estepar R, Folch E, Onieva J, Gangadharan S, Majid A. Three-dimensional printing and 3D slicer: powerful tools in understanding and treating structural lung disease. Chest. 2017; 149: 1136-1142.

[64] Freitag L, Tekolf E, Steveling H, Donovan TJ, Stamatis G. Management of malignant esophagotracheal fistulas with airway stenting and double stenting. Chest. 1996; 110: 1155-1160.

[65] Youness HA, Harris K, Awab A, Keddissi JI. Bronchoscopic advances in the management of aerodigestive fistulas. Journal of Thoracic Disease. 2018; 10 : 5636-5647. 
[66] Ke M, Wu X, Zeng J. The treatment strategy for tracheoesophageal fistula. Journal of Thoracic Disease. 2015; 7: S389-S397.

[67] Huang P, Lee J. Are single or dual luminal covered expandable metallic stents suitable for esophageal squamous cell carcinoma with esophagoairway fistula? Surgical Endoscopy. 2017; 31: 1148-1155.

[68] Herth FJF, Peter S, Baty F, Eberhardt R, Leuppi JD, Chhajed PN. Combined airway and oesophageal stenting in malignant airwayoesophageal fistulas: a prospective study. European Respiratory Journal. 2010; 36: 1370-1374.

[69] Agrafiotis M, Siempos II, Falagas ME. Infections related to airway stenting: a systematic review. Respiration. 2009; 78: 69-74.

[70] Dutau H, Di Palma F, Thibout Y, Febvre M, Cellerin L, Naudin F, et al. Impact of silicone stent placement in symptomatic airway obstruction due to non-small cell lung cancer - a french multicenter randomized controlled study: The SPOC Trial. Respiration. 2020; 99: 344-352.

[71] Dutau H, Dumon J. Airway Stenting Revisited: 30 Years, the Age of Reason? Journal of Bronchology \& Interventional Pulmonology. 2017; 24: $257-259$.

[72] Ost DE, Ernst A, Grosu HB, Lei X, Diaz-Mendoza J, Slade M, et al. Complications following therapeutic bronchoscopy for malignant central airway obstruction: results of the AQuIRE registry. Chest. 2015; 148: 450-471.

How to cite this article: Alessandro Bandiera, Paola Ciriaco, Angelo Carretta, Giampiero Negri. The role of rigid bronchoscopy in complex airway disorders. Signa Vitae. 2021;17(2):39-47. doi:10.22514/sv.2021.017. 